\title{
The burden of osteoporosis in Brazil
}

\author{
O ônus da osteoporose no Brasil
}

Bruna Coelho Galvão Marinho',2, Luiza Paulino Guerra', Juliana

Beaudette Drummond ${ }^{3}$, Barbara C. Silva ${ }^{4}$, Maria Marta Sarquis Soares ${ }^{5}$

\author{
${ }^{1}$ Hospital Felício Rocho, Belo \\ Horizonte, MG, Brazil \\ 2 Faculdade de Medicina, \\ Universidade José do Rosário \\ Vellano (Unifenas), Campus Belo \\ Horizonte, Alfenas, MG, Brazil \\ ${ }^{3}$ Laboratório Hermes Pardini, \\ Belo Horizonte, MG, Brazil \\ ${ }^{4}$ INCT, Medicina Molecular, \\ Faculdade de Medicina, \\ Universidade Federal de \\ Minas Gerais (UFMG), Belo \\ Horizonte, MG, Brazil \\ ${ }^{5}$ Faculdade de Medicina, UFMG, \\ Belo Horizonte, MG, Brazil
}

\begin{abstract}
Osteoporotic fractures impose severe physical, psychosocial, and financial burden both to the patient and the society. Studies on the prevalence of osteoporosis and fragility fractures in Brazil show a wide variation, due to differences in sample size, the population studied, and methodologies. Few studies have been conducted in Brazil about the cost-effectiveness analyses of different intervention options aimed at the diagnosis and treatment of osteoporosis. Investigation and treatment strategies based on cost-effectiveness and scientific evidence are essential in the preparation of public health policies with the ultimate goal of reducing the incidence of fractures and, consequently, the direct and indirect costs associated with them. This article reviews the Brazilian burden of osteoporosis in terms of the prevalence and fractures attributable to the disease, the costs related to the investigation and management, as well as the impact of osteoporosis on the population as a whole and on affected individuals. Arq Bras Endocrinol Metab. 2014;58(5):434-43
\end{abstract}

Keywords

Expenses; osteoporosis; Brazil

\section{RESUMO}

Fraturas osteoporóticas impõem graves entraves físicos, psicossociais e financeiros, tanto para o paciente quanto para a sociedade. Estudos sobre a prevalência de osteoporose e fraturas por fragilidade no Brasil mostram uma grande variação, em decorrência das diferenças no tamanho das amostras, da população estudada e da metodologia empregada. Poucos estudos têm sido realizados no Brasil sobre a análise de custo-efetividade das diferentes opções de intervenção que visam ao diagnóstico e ao tratamento da osteoporose. Estratégias de investigação e de tratamento com base na relação custo-eficácia e evidências científicas são essenciais para a elaboração de políticas de saúde pública, com o objetivo final de reduzir a incidência de fraturas e, consequentemente, os custos diretos e indiretos associados a elas. Este artigo faz uma revisão sobre o ônus da osteoporose no Brasil em termos de prevalência e fraturas atribuíveis à doença, de custos relacionados com a investigação, tratamento da osteoporose, bem como seu impacto na população como um todo e em indivíduos afetados. Arq Bras Endocrinol Metab. 2014;58(5):434-43

Descritores

Gastos; osteoporoses; Brasil

\section{INTRODUCTION}

$\mathrm{O}$ steoporosis is a major health concern with up to 9 million new osteoporotic fractures expected annually worldwide $(1,2)$. Osteoporotic fractures impose severe physical, psychosocial, and financial burden both to the patient and the society. They may be accompanied by pain, bone deformities, fear, distress, difficulty in performing daily activities, loss of independence, and institutionalization (3). More important, fragility fractures are associated with high mortality rates that can exceed $20 \%$ in the first year after the fracture $(4,5)$. These devastating consequences of osteoporotic fractures result in high economic costs to society, as fractures generate expenses with medical treatment, surgeries, hospital stays, and rehabilitation. These costs tend to rise with the aging of the population and, consequently, greater prevalence of osteoporosis and its complications (6). 
Osteoporosis is a "silent" disorder until it leads to one or more fractures (7). Since the treatment of osteoporosis can reduce the fracture risk, the early detection of osteoporosis by the measurement of bone mineral density (BMD) by dual-energy X-ray absorptiometry (DXA) should be targeted in clinical practice (8). In fact, according to the 2002 Brazilian Consensus of Osteoporosis, BMD measurements should be performed in a number of settings - and as a rule, for all women over 65 years of age and men over 70 years $(9)$.

This article reviews the Brazilian burden of osteoporosis in terms of the prevalence of osteoporosis and fractures attributable to the disease, the costs related to its management and its impact on the population as a whole and on affected individuals.

\section{MATERIALS AND METHODS}

We searched for English- and Portuguese-language articles, in human subjects, available in full electronic media in MedLine (PubMed) and the database of the Latin American and Caribbean Literature on Health Sciences (LILACS) published within all dates. The search terms used were "osteoporosis" and "Brazil" in addition to one of the following: "costs or expenditure", "burden", "prevalence", "fracture", "quality of life", or "impact". Relevant articles were reviewed in detail. Pertinent data concerning the demographic profile of the Brazilian population were also used. Furthermore, author's work published as an abstract regarding the direct costs related to the biochemical workup in the management of osteoporosis was also reviewed (10).

\section{DEMOGRAPHIC PROFILE OF THE BRAZILIAN POPULATION}

According to the 2010 census, conducted by the Instituto Brasileiro de Geografia e Estatistica (IBGE), the Brazilian population in 2010 was $190,755,799$ and table 1 shows our demographic profile in 2000 and 2010 . The percentage of elderly individuals increased in 2010 relative to 2000 (11) and consequently the prevalence of diseases such as osteoporosis is expected to rise. In 2010, there were more than 20 million Brazilians over 65 years of age, and the projection for this segment of the population is to exceed 50 million by $2050(11,12)$. Moreover, $20.45 \%$ of the population was older than 50 years in 2010 . Women over 65 years of age accounted for $4.18 \%$ of the population, while men over 70 years of age corresponded to $2.04 \%$ (Table 1$)(11,12)$.
Table 1. Demographic characteristics of the Brazilian population in 2000 and 2010

\begin{tabular}{lcc}
\hline Year & $\mathbf{2 0 0 0}$ & $\mathbf{2 0 1 0}$ \\
\hline Overall population & $169,799,170$ & $190,755,799$ \\
Population $>50$ years & $27,053,620$ & $39,007,220$ \\
\% population $>50$ years & 15.93 & 20.45 \\
Population women $>65$ years & $5,555,365$ & $7,966,402$ \\
\% population women $>65$ years & 3.27 & 4.18 \\
Population men $>70$ years & $2,740,205$ & $3,891,013$ \\
\% population men $>70$ years & 1.61 & 2.04 \\
Life expectancy & 70.4 years & 73.48 years \\
\hline
\end{tabular}

Source: Instituto Brasileiro de Geografia e Estatística (IBGE) (11).

\section{PREVALENCE OF OSTEOPOROSIS IN BRAZIL}

In Latin America, the estimated prevalence of spine osteoporosis in women aged 50 years and more ranges from $12.1 \%$ to $17.6 \%$, while that of femoral neck osteoporosis ranges from $7.9 \%$ to $22 \%$ (13). Brazil is a country of extensive race mixing and heterogeneous regional distribution, which implies different risk factors for osteoporosis and fractures (14). Moreover, access to BMD testing, which is essential for the detection of osteoporosis and intervention before fracture occurs, is still sparse in Brazil. The poor instrument availability, high cost to patients and restrictive indications for BMD testing constitute the major barriers for the access to such testing in Brazil. Despite these limitations, few studies have evaluated the prevalence of osteopenia and osteoporosis in Brazil, which shows a wide variation, due to differences in sample size, eligibility criteria, and methodologies, as showed in table 2 (15). Overall, the prevalence of osteoporosis in Brazilian studies ranges from $6 \%$ to $33 \%$ depending on the population and other variables evaluated (16-18).

Baccaro and cols. have evaluated, by questionnaire, the prevalence of osteoporosis and its associated factors in 622 Brazilian women over 50 years of age. The prevalence of self-reported osteoporosis was 21.3\% (19). Using BMD for diagnosis, in 2011, Buttros and cols., found in a cross-sectional study $24.6 \%$ of osteoporosis and $43.6 \%$ of osteopenia in 431 postmenopausal women (aged $40-75$ years) evaluated (20). The São Paulo Osteoporosis Study (SAPOS) estimated the prevalence of osteoporosis and low-trauma fracture in 4,332 women over 40 years of age. BMD at the lumbar and femoral sites was measured by DXA in all participants, and the prevalence of osteoporosis was 33\% (18). 
Table 2. Prevalence of osteoporosis based on different studies in the Brazilian population

\begin{tabular}{lccccc}
\hline Reference & Year of publication & Number of participants & Age (years) & Prevalence & Diagnostic method \\
\hline Baccaro and cols. (19) & 2013 & 622 women & $>50$ & $21.3 \%$ & Self-report \\
Buttros and cols. (20) & 2011 & 431 women & $40-75$ & $24.6 \%$ & BMD \\
Pinheiro and cols. (24) & 2010 & 2,420 subjects (70\% women) & $>40$ & $6 \%$ & Self-report \\
Pinheiro and cols. (18) & 2010 & 4,332 women & $>40$ & $33 \%$ & BMD \\
Martini and cols. (12) & 2009 & 54,369 (33075 women) & $\geq 18$ & $4.4 \%$ total & Self-report \\
& & & & $33 \%$ & BMD \\
\hline Camargo and cols. (17) & 2005 & 391 (207 women) & & & 370 \\
\hline
\end{tabular}

The overall prevalence of osteoporosis appears to be lower when women and men are included in the evaluation. The Brazilian Osteoporosis Study (BRAZOS), which evaluated a representative sample of $2,420 \mathrm{Bra}-$ zilian individuals (women, $70 \%$ ) $>40$ years old, from different regions and economic classes revealed that the self-reported prevalence of osteoporosis was only $6 \%$ (16). Camargo and cols. assessed the BMD of 301 individuals ( 207 women) older than 70 years of age from different clinical centers in the city of São Paulo. The prevalence of osteoporosis ranged from $6.4 \%$ to $16.1 \%$ in men, and from $22.2 \%$ to $33.2 \%$ in women in the different centers studied (17).

Another cross-sectional study conducted in São Paulo evaluated 2,143 subjects $\geq 60$ years old interviewed in the years of 2000 and 2006 (21). The prevalence of osteoporosis, assessed by self-report, was greater among subjects with private health insurance coverage than in those without private insurance, regardless of sex and year of evaluation. This finding may represent a wider access to DXA tests and better understanding of the disease among those with private health insurance.

Finally, in a cross-sectional study based on data from the VIGITEL system (Risk Factor Surveillance and Protection against Chronic Diseases through Telephone Survey) conducted in 2006, 54,369 Brazilian individuals $(33,075$ women $)>18$ years of age were interviewed. The prevalence of osteoporosis as assessed by self report was $4.4 \%$ in the entire population, $7 \%$ in women and $1.3 \%$ in men (12). This lower prevalence of osteoporosis as compared to the previous studies reported here may be explained by the low age of subjects included.

\section{INCIDENCE AND PREVALENCE OF OSTEOPOROTIC FRACTURES}

There are few consistent data on the prevalence and relevance of risk factors for osteoporotic fracture avail- able in Latin America and Brazil. A review of Latin American studies showed that the incidence of osteoporotic hip fractures ranged from 40 to 362 per 100,000 persons of 50 years or older, with a female-to-male ratio of 3:1. The majority of the studies showed lower incidence of hip fractures in the Latin American population compared with the population of the United States, Canada, and Europe. This discrepancy was likely due to differences in the studied population, the adopted definition of case, and methodological issues (13).

The Latin American Vertebral Osteoporosis Study (LAVOS) evaluated a randomized sample of 1,922 women aged 50 years and older from Argentina, Brazil, Colombia, Mexico, and Puerto Rico (22). The prevalence of vertebral fractures as assessed by lateral X-rays of the lumbar and thoracic spine was $11.18 \%$, and was similar in the five countries. Among women aged 50 to 59 years, the prevalence was $6.9 \%$, which increased to $27.8 \%$ for those aged 80 years or older.

Studies exclusively conducted in Brazil show that the incidence of osteoporotic fractures varied with the population and the fracture site investigated. Overall, the age-adjusted annual incidence of fractures varied from 5.59 to 13 per 10,000 in women, and from 12.4 to 27.7 per 10,000 in men (16). The lowest incidences of fractures in the above ranges, both in women and men, correspond to the incidence of hip fractures in Sobral, a city located in the Northeast Region of Brazil $\left(3^{\circ} \mathrm{S} / 40^{\circ} \mathrm{E}\right)(23)$.

In BRAZOS, 2,420 Brazilian individuals from the five geographic regions of the country were evaluated. The prevalence of self-reported fragility fractures defined as that resulting of any fall from standing height or less in subjects > 40 years old, was $12.8 \%$ in men and $15.1 \%$ in women. Statistically significant differences among Brazilian regions, according to gender or social class, were not observed (24). 
Siqueira and cols. evaluated the prevalence of selfreported fractures and its association with socio-demographic variables and medical diagnosis of osteoporosis in 3,100 individuals from Pelotas, a Southern Brazilian city $(56.6 \%$ women $)(25)$. The lifetime prevalence of any type of fracture was $37.5 \%$ among men and $21.3 \%$ among women $(\mathrm{P}<0.001)$. While in men most fractures were caused by sports practice and happened in leisuretime, most fractures in women were caused by falls and occurred inside the home. The prevalence of fractures throughout life was almost twice as higher $(28.3 \%)$ than that observed in the BRAZOS study (14.4\%) $(24,25)$. It is important to emphasize that individuals aged 20 years or more were included in Siqueira's study, as well as trauma-related and non-traumatic fractures.

In the SAPOS study, the prevalence of self-reported osteoporotic fractures was $11.5 \%$, with a mean age of $65.5 \pm 10$ years at the time of the event. Among the 497 women with fractures, vertebral fractures were reported in $6 \%$, non-vertebral fractures in $86 \%$ (including the humerus, distal forearm, metacarpus, ribs, and hip) and femoral fractures in $8 \%$ of the cases (18).

A cross-sectional study conducted in Chapecó, a Southern Brazilian city, explored the prevalence of asymptomatic vertebral fractures by radiographs, in a population of 186 postmenopausal women over 60 years (26). Almost half of the women studied (48.9\%) had at least one vertebral fracture not associated with a prior history of fracture. The higher prevalence of vertebral fractures in this study was mainly attributed to the criteria used for the analysis and definition of vertebral fractures, the population studied (all subjects were white), the high frequency of risk factors such as glucocorticoid use, low dietary calcium intake, and alcohol abuse, and the latitude of the city (below the equator) (26).

In the city of São Paulo, Lopes and cols. evaluated 1,007 elderly subjects ( 600 women) using BMD testing of hip and lumbar spine (27). The prevalence of osteoporotic fractures assessed by self-report was $13.2 \%$ and the major sites affected were distal forearm $(6.0 \%)$, humerus $(2.3 \%)$, femur (1.3\%), and ribs (1.1\%). Women had greater prevalence of fractures $(17.5 \%)$ compared with men $(6.9 \%)(27)$.

In the city of Campinas, Baccaro and cols. evaluated 622 women aged 50 years or older and the overall prevalence of self-reported bone fragility fractures was $10.8 \%$, whereas the prevalence of femoral/hip fractures was $1.8 \%$. In the multiple regression analysis, a higher prevalence of fragility fractures was associated with a longer time since the menopause and the presence of osteoporosis (19).

\section{IMPACT OF FRAGILITY FRACTURES ON THE INDIVIDUAL}

Osteoporosis poses a significant negative impact on the quality of life of patients, particularly after fragility fractures, which is supported by the majority of the studies reviewed below.

Osteoporotic fractures, commonly of the hip and spine, often result in secondary complications, such as functional impairment, increased hospital stays that may result in further health problems, increased medical costs, and increased dependence on others for living assistance (28). In addition to the evident physical and functional consequences, such as kyphosis, restriction of movement, and pain, the individual with osteoporosis may sustain a psychosocial impact. Many patients, in the early stages of the disease, express marked anxiety, especially regarding the possibility of future fractures and physical deformity. As the disease progresses, depression may be aggravated for those who sustain hip fractures or multiple vertebral fractures. Osteoporosis can lead to dependence, functional disability, and lowered self-esteem (29). Among Brazilian women over 45 years of age, $84 \%$ are concerned about having osteoporosis, and $13 \%$ of them have sustained at least one fragility fracture after the age of 40 . Among women who had fractures, $52 \%$ reported worsened quality of life following the fracture (29).

The BRAZOS study showed a strong association between poor quality of life and the presence of lowimpact fractures, both in men and women older than 40 years of age, emphasizing that patients with osteoporosis and fractures have a higher incidence of chronic pain, decreased physical capacity, reduction in social activities, decreased perception of well- being, and depressed mood than individuals without fractures (16).

In a study that evaluated 56 elderly patients $\geq 60$ years old with a low-trauma hip fracture, from the Brazilian city of São Paulo, there was an increase in the inability to walk and in the use of a supporting device. The hip fracture also led to a significant reduction in the functional ability to perform basic and instrumental activities of daily living (30).

Even asymptomatic vertebral fractures can negatively impact the quality of life. In a Brazilian cross-sectional study including 180 women aged 65 years and older 
with or without vertebral fractures, the quality of life was assessed by the European quality of life questionnaire (Quality of Life Questionnaire of the European Foundation for Osteoporosis - QUALEFFO-4l) (31). The presence of asymptomatic vertebral fractures identified on thoracic and lumbar spine radiographs was associated with a reduced quality of life regardless of age, BMI, and level of physical activity (31).

Another study assessed the prevalence and the association between the number of vertebral fractures and quality of life in 126 postmenopausal Brazilian osteoporotic women (mean age 65.7 years). The prevalence of vertebral fractures identified on thoracic and lumbar spine radiographs was $34.1 \%$. While the QUALEFFO-41 questionnaire showed no difference in scores between women with and without vertebral fractures, there was a direct correlation between the quality of life score and the number of vertebral fractures (32).

Fortes and cols. evaluated the morbidity and mortality deriving from proximal femoral fractures in individuals over 60 years of age who were admitted to two hospitals in the city of São Paulo (33). A marked decrease was noted in the indicators of functional disability evaluated using the Health Assessment Questionnaire (HAQ), after six months of the fracture event. The factors that correlated with poorer functional ability were HAQ score prior to fracture, institutionalization after fracture and age. Six months after the event, $11.6 \%$ of the patients had become completely dependent and 9.3\% were institutionalized (33).

\section{IMPACT OF OSTEOPOROSIS AND FRAGILITY FRACTURES ON SOCIETY}

\section{Mortality}

Hip fracture is one of the most feared consequences of osteoporosis. Hip fractures are associated with high post fracture disability, increased mortality, and high healthcare expenditures (34). The mortality rate from hip fractures in developed countries is around $25 \%$ in the first year after the event $(4,5)$. Mortality rates during the hospitalization period range from $1.02 \%$ to $10 \%$ across countries (13).

In Brazil, it is estimated that $15 \%$ to $30 \%$ of patients with hip fractures die within the first year following the event, frequently as a result of fracture complications such as infections, venous thrombosis, and pressure ul- cers, or comorbid conditions, especially cardiovascular diseases. The predominant factors related to increased risk of death are male gender, old age, impaired functional ability prior to the fracture, greater number of comorbidities, sarcopenia and a fragile phenotype (15).

A study analyzed the profile of the Brazilian public health care system (SUS) admissions due to osteoporotic hip fracture in patients over 60 years, in the years 2006 to 2008 in different regions of Brazil. The mortality rate due to femoral fracture was higher in females then in males ( 3.5 versus 1.9 per 1,000 elderly, respectively, in 2006, with similar rates in 2007 and 2008), which is in disagreement with other Brazilian studies. The proportion of outcomes of death increased with advancing age in the three analyzed years and the Southeast region had the highest percentage of deaths for elderly patients hospitalized with hip fracture (35).

A prospective study published in 2009 investigated the mortality rate in the first year after hip fractures, as well as the factors associated with mortality in Brazilian patients. In total, 246 individuals older than 60 years were followed for one year after hospitalization for hip fractures. Eighty-six patients died (35\%), with most of those deaths $(74.4 \%)$ occurring after hospital discharge. Of the 67 men, 29 died (43.3\%), and of the 179 women, 57 died $(31.8 \%)$ within the first year after fracture. Functional status prior to the fracture, age, male gender, and high surgical risk increased mortality risk, while antibiotics use and physical activity after the surgery reduced the risk (34).

A similar study conducted in Rio de Janeiro, showed a $21.5 \%$ overall mortality in the first year after hip fractures. Most of those deaths (55.1\%) also occurred after hospital discharge, and were chiefly associated with cardiovascular events or infections (36).

Finally, a Brazilian study involving 56 elderly individuals from São Paulo showed a mortality rate of $23.2 \%$ over the six months following a hip fracture. The most frequent causes of death were infectious $(46.1 \%)$, cardiovascular $(46.1 \%)$ or indeterminate $(7.8 \%)(33)$.

Besides the impact of osteoporotic fracture, a Brazilian study linked low BMD with increased cardiovascular mortality. This prospective cohort of 275 postmenopausal elderly women with a 5-year follow-up showed a clear association between low BMD at the femoral sites and increased overall and cardiovascular mortality, regardless of age, weight, body mass index, smoking status, previous fracture, physical activity, drug use, and presence of chronic diseases (37). 


\section{Direct costs}

The costs to society can be divided into direct and indirect, and are related both to the prevention and treatment of osteoporosis and rehabilitation following the fracture. These costs vary widely between countries, not only due to the varying incidence rates of the disease, but also because of the different degrees of emphasis placed on prevention, hospitalization, and treatment (38).

\section{Direct costs related to the management of osteoporosis: the biochemical workup}

During the investigation of a low BMD, a biochemical workup aimed primarily at the detection of secondary causes of osteoporosis is indicated. The extent of the workup may vary according to the recommendation of each clinical institution or reference Service. Various disorders affecting bone mass are common and of easy diagnosis and treatment. Some tests are key in the investigation of secondary factors that interfere with bone mass, such as serum levels of calcium, parathyroid hormone (PTH), 25-hydroxy vitamin D (25OHD), thyroid-stimulating hormone (TSH), and 24-h urine calcium. While patients with a clinical suspicion of secondary conditions should have extended diagnostic workup, the costs of ordering more complex tests for all patients with osteoporosis have not been estimated (10).

Several studies have demonstrated the importance of laboratory studies in patients with osteoporosis (3942 ). Our group evaluated the frequency and cost-effectiveness of the tests ordered for postmenopausal women who had been diagnosed as having osteoporosis based on BMD by DXA (10). The study was conducted in an outpatient clinic of general endocrinology in Belo Horizonte, Brazil, and in total, 185 medical records of postmenopausal women were reviewed. Patients with kidney or liver failure, or known to have a condition or a medication history that could cause bone loss were excluded. Of the 185 patients evaluated, 108 exhibited one or more abnormal tests (126 laboratory abnormalities) indicative of disorders that could contribute to decreased bone mass or compromise the efficacy of the osteoporosis treatment (Table 3 ) (10).

In this study, serum calcium was the most frequently ordered test ( $100 \%$ of the patients) (Table 4 ); however, calcium concentrations were outside the reference range in only $9 \%$ of the patients (Table 4 ). The 25OHD test, which was ordered for $82 \%$ of the patients, was altered
Table 3. Laboratory abnormalities found in the workup for primary osteoporosis at the General Endocrinology Service $(n=185)$

\begin{tabular}{lc}
\hline Laboratory abnormality & Number \\
\hline $250 \mathrm{HD}<30 \mathrm{ng} / \mathrm{mL}$ & 64 \\
Hypocalciuria & 1 \\
Hypercalciuria & 16 \\
Primary hyperparathyroidism & 14 \\
Normocalcemic hyperparathyroidism & 16 \\
latrogenic hyperthyroidism & 9 \\
Monoclonal gammopathy of undetermined significance & 4 \\
Acromegaly & 2 \\
Total & 126 \\
\hline
\end{tabular}

Source: Marinho BCG, Soares MMS. Custo-efetividade da investigação laboratorial da

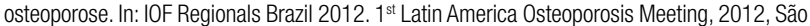
Paulo. Arch Osteoporos. 2012;7:S191.

Table 4. Frequency of ordered tests and its abnormalities found by the General Endocrinology Service for osteoporosis workup $(n=185)$

\begin{tabular}{lcc}
\hline Laboratory tests & $\begin{array}{c}\text { Number (\%) of } \\
\text { tests ordered }\end{array}$ & $\begin{array}{c}\text { Number (\%) of } \\
\text { abnormal tests }\end{array}$ \\
\hline Serum calcium & $185(100 \%)$ & $16(9 \%)$ \\
TSH & $175(95 \%)$ & $22(13 \%)$ \\
Complete blood cell count & $173(94 \%)$ & $8(5 \%)$ \\
PTH & $152(82 \%)$ & $54(36 \%)$ \\
$250 H D$ & $152(82 \%)$ & $64(42 \%)$ \\
Phosphate & $140(76 \%)$ & $4(3 \%)$ \\
$24-h$ urine calcium & $124(67 \%)$ & $23(19 \%)$ \\
Protein electrophoresis & $44(24 \%)$ & $6(14 \%)$ \\
Cortisol & $16(9 \%)$ & 0 \\
Antigliadin antibody & $12(6 \%)$ & 0 \\
IGF-1 (somatomedin) & $5(3 \%)$ & $2(40 \%)$ \\
\hline
\end{tabular}

Source: Marinho BCG, Soares MMS. Custo-efetividade da investigação laboratorial da

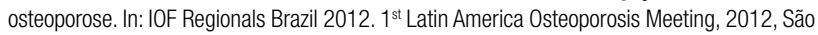
Paulo. Arch Osteoporos. 2012;7:S191.

in $42 \%$ the study population (10). A high proportion of acromegaly diagnoses was noted (two abnormal tests in five ordered), which might be explained by the fact that the study was conducted in a referral center, where the degree of suspicion of endocrine diseases is high. None of the patients had the diagnosis of Cushing syndrome, and of note, antigliadin antibodies were negative in all patients tested (10). These findings corroborate what had been published in similar studies in other countries. In the study by Tannenbaum and cols., $1.8 \%$ of patients had celiac disease, while $0.6 \%$ had Cushing syndrome (42). Rajeswaran and cols. found $4.23 \%$ of patients with celiac disease and no Cushing syndrome (43). Cushing syndrome accounts for 5-10 cases/million/year (44) and celiac disease has a prevalence of $1 \%(45)$. There- 
fore, it is likely that these diseases were not found in the present study because of the population sample size (small in relation to the prevalence of these two diseases, especially Cushing syndrome) and the reduced number of screening tests performed (antigliadin antibody and cortisol levels were measured in 6\%, and 9\% of the patients, respectively).

In order to assess the cost-effectiveness of different testing strategies for the diagnosis of secondary causes of osteoporosis, we further evaluated a subgroup of 62 patients with no treatment for osteoporosis who underwent all the tests of a basic workup routine, which were: serum calcium, 24-h urine calcium, PTH, 25OHD, and TSH. This workup was selected based on different recommendations of several Societies $(7,40,42,43,46)$. The strategy of ordering PTH, 24-h urine calcium and $25 \mathrm{OHD}$ for all patients, and TSH for those in use of levothyroxine, resulted in $100 \%$ of diagnoses at a cost of 69.7 U.S. dollars (USD) per patient screened and 84.7 USD per diagnosis. The testing strategy that proposes ordering PTH and 24-h urine calcium measurements for all patients, 25OHD for those with an abnormal PTH and/or urinary calcium, and TSH for the levothyroxine users identifies $84.31 \%$ of the disorders at a lower cost, of 55.6 USD per patient and 80.2 USD per diagnosis (10). The current cost of different diagnostic tests for osteoporosis in Brazil is depicted in table 5 .

Table 5. Costs in U.S. dollar (USD) of diagnostic tests for osteoporosis

\begin{tabular}{|c|c|c|}
\hline Test & SUS rate (USD) & $\begin{array}{l}\text { Private healthcare } \\
\text { system rate (USD) }\end{array}$ \\
\hline DXA 2 sites & 31.1 & 42.7 \\
\hline Total calcium & 1.0 & 1.9 \\
\hline Ionized calcium & 2.0 & 5.4 \\
\hline Phosphate & 1.0 & 1.9 \\
\hline Complete blood cell count & 2.3 & 4.1 \\
\hline TSH & 5.1 & 8.1 \\
\hline Liver function (AST, ALT) & 2.3 & 3.8 \\
\hline Testosterone (men) & 5.9 & 10.0 \\
\hline Erythrocyte sedimentation rate & 1.5 & 1.4 \\
\hline Creatinine & 1.0 & 1.9 \\
\hline 24-h urine calcium & 1.9 & 1.9 \\
\hline 24-h creatinine & 1.9 & 1.9 \\
\hline $250 \mathrm{HD}$ & 24.9 & 9.4 \\
\hline PTH & 24.4 & 27.1 \\
\hline Alkalyne phosphatase & 1.1 & 2.4 \\
\hline Total protein and fractions & 1.0 & 2.0 \\
\hline Lumbar spine X-ray, 1 view & 5.5 & 15.5 \\
\hline
\end{tabular}

\section{Direct costs related to the management of osteoporosis: treatment}

It is estimated that SUS accounts for the provision of healthcare to $75.5 \%$ of the Brazilian citizens, and medications represent a sizable fraction of the public spending with health (47). The expenses of Brazil's Ministry of Health with drugs acting on bone structure and mineralization correspond to approximately $10.9 \%$ of the total spending with high-cost medications (48). In the São Paulo public health system, in 1998, the mean annual cost for postmenopausal osteoporosis treatment in ambulatory patients amounted to 775 dollars per patient, and out-of-the-pocket payments by the patients corresponded to $9 \%$ of the monthly family income (49). In Minas Gerais State, Brandao and cols. examined a historical cohort of 72,265 women, mean age $64.8 \pm 9.8$ years old, who used high-cost medications supplied by the SUS to treat postmenopausal osteoporosis in the period 2000 to 2006 (50). The study demonstrated that the mean monthly per capita expenditure in the first year of treatment was 51 USD, and this gradually increased with increasing age from 50 years. The average monthly expenditure was 3.9\% greater in women aged 50 to 59 years than in women $<49$ years old. Similarly, the monthly expenditure was $55.8 \%$ greater in women who had sustained a fragility fracture as compared to those without fractures. A total of $6,429(8.9 \%)$ patients died during the study period. The average monthly per capita expenditure was $2.2 \%$ higher in women who died than in those who were alive at the end of the study $(\mathrm{p}=0.02)$. The most commonly used drug at the beginning of the treatment was alendronate $(57 \%)$, followed by calcitonin $(24.6 \%)$ and raloxifene (15.5\%). The type of anti-osteoporosis therapy used was the variable with the highest impact on the average monthly per capita expenditure, with tamoxifen and calcitonin having the greatest impact on the mean monthly spending, using alendronate as the standard drug (50).

Hip fractures typically demand in-hospital care, while hospitalization is less frequent in vertebral, wrist, and other fractures (15). A recent study evaluated the profile of SUS hospitalizations for the treatment of femoral osteoporotic fracture in elderly patients in Brazil between 2006 and 2008 (35). Over this 3-year period, $1 \%$ of the senior citizens hospitalized had a femoral fracture as the primary diagnosis. The total spending with hospital stays for femoral fractures in the elder- 
ly population in Brazil, including intensive care unit stays, prostheses and ortheses expenses, added up to $17,437,273.50$ USD in $2006,21,067,819.40$ USD in 2007 , and $27,358,429.50$ USD in 2008 , which corresponded to $2 \%$ of the total spending with hospitalization for the elderly (35). The mean cost of treating a femoral fracture in two hospitals that maintained an agreement with the SUS ranged between 994.32 USD and 4,215.79 USD. This was a comprehensive analysis and included direct costs of staff (medical, nurse and physiotherapy services) as well as hospital resources (emergency room, operating room, intensive care unit, medications, prostheses, laboratory and imaging exams). This great disparity is due to the fact that cost analysis methodologies vary between hospitals (51). These figures contrast with the mean cost of hospitalization for osteoporotic femur fractures in individuals older than 50 years of age in the Brazilian private healthcare system, which amounted to 10,104.00 USD according to a study conducted between 2003 and 2004 (52). This number is closer to direct hospital-related costs reported in other countries, which suggests that the costs calculated by the hospitals with an agreement with the SUS are lower than the actual cost of the treatment for acute femur fracture. Femoral fractures were observed in $4.99 \%$ of the 129,611 cases of osteoporosis managed within the private healthcare system. The annual economic burden of these fractures for the health insurance companies was estimated in approximately 6 million USD $(15,52)$. However, these results do not provide consistent data on the total costs over the medium and long term (15).

Regarding pharmacoeconomic analyses, a Brazilian study performed a systematic review of the strategies used in Brazil and worldwide, focusing on the treatment of osteoporosis in postmenopause. The use of bisphosphonates was the most extensively evaluated strategy, and produced the best cost-effectiveness. Hormone therapy, calcium and vitamin D supplementation, strontium ranelate, raloxifene, teriparatide, and denosumab were also evaluated, with varying outcomes. Given the particularities of the Brazilian context, it was impossible to extrapolate any of the external results to our population, which restricted the applicability of such results to the decision-making process in public health policies (38).

Cost-effectiveness analyses of different intervention options aimed at the diagnosis and treatment of osteoporosis, with the ultimate goal of reducing the in- cidence of fractures and, consequently, the direct and indirect costs associated with them, are paramount in the preparation of public health policies. Few studies have been conducted in Brazil in this regard. In 2003, Silva and cols., using the decision tree tool, calculated in $34,800.00$ USD the cost per fracture that could be spared if the BMD/alendronate intervention were applied to women over 65 years of age, and in 4,315.00 USD if only the association of calcium and vitamin D were used (53). Both estimates far exceeded the mean cost to treat femoral fractures (750.00 USD) estimated from DATASUS 2001 data, which led the authors to question the indication to implement any prevention and treatment strategy, given the limited resources. The analysis that those authors undertook was preliminary and shows methodological shortcomings, yet it reinforces the need for enhanced knowledge of cost analysis strategies in our setting. In 2008, Araújo and cols. evaluated the cost-effectiveness of the osteoporosis treatment with zoledronic acid in the Brazilian private healthcare system, in a hypothetical cohort of women over 65 years of age using the Markov model (54). The use of zoledronic acid has proved to be cost-effective in the prevention of proximal femur fracture in that specific setting; however, these data cannot be extrapolated to the public system or to other sites of osteoporotic fractures. Additionally, the use of new tools enabling the calculation of individual risks of fracture based on clinical estimators, such as FRAX Brazil (Fractures Risk Assessment) and SAPORI (São Paulo Osteoporosis Risk Index), could contribute to a more effective use of the available diagnostic and therapeutic resources (55).

\section{Indirect costs}

In addition to imposing direct medical costs to society, osteoporosis also entails indirect costs, especially those related to reduced productivity, disability and early deaths. It is difficult to measure and evaluate the impact of indirect costs. One method quantifies loss of productivity based on profit reduction. Considering that bone diseases affect a large number of retired individuals, indirect costs are underestimated by this approach. However, assuming that people are worth what they earn, a study estimates that the cost of premature deaths and restricted activities resulting from fractures account for $26 \%$ of the total cost with fractures, and $12 \%$ of the costs deriving from hip fractures (7). In Brazil, there are no studies assessing the specific burden of the indirect costs of osteoporosis on society. 


\section{CONCLUSIONS}

Osteoporosis is a disabling disease associated with high rates of morbidity and mortality. The projected number of individuals with osteoporosis in Brazil will increase as the population ages, which may have serious economic impact on our society and on the quality of life of the affected individuals.

In spite of the heterogeneity of Brazilian studies, the overall prevalence of osteoporosis and fragility fractures in our country is high. In addition to the different ways to assess osteoporosis (e.g. self-report vs. DXA), the sociodemographic characteristics of our population also influence the results found.

There are few Brazilian studies of cost-effectiveness strategies used in the workup and treatment of osteoporosis. Non-pharmacological strategies should always be considered, however without neglecting the proven efficacy of the various pharmacological options available. Early detection and sensible use of antifracture medications are invaluable in reducing the morbidity and mortality deriving from fractures. More comprehensive, multicentric studies are needed to enable us to outline evaluation and treatment protocols for our population.

Public policies aiming at the education of the population regarding the importance of osteoporosis prevention, which should be initiated in childhood and adolescence, could minimize the future economic burden of the disease.

Disclosure: no potential conflict of interest relevant to this article was reported.

\section{REFERENCES}

1. Johnell O, Kanis JA. An estimate of the worldwide prevalence and disability associated with osteoporotic fractures. Osteoporos Int. 2006;17(12):1726-33.

2. Kanis J. Assessment of osteoporosis at the primary health care level. WHO Scientific Group Technical Report, on behalf of the World Health Organization Scientific Group 2007. Available at: http://www.shef.ac.uk/FRAX/pdfs/WHO_Technical_Report.pdf.

3. Gold D. The clinical impact of vertebral fractures: quality of life in women with osteoporosis. Bone. 1996;18(2 Suppl):185S-9S.

4. Browner WS, Pressman AR, Nevitt MC, Cummings SR. Mortality following fractures in older women. The study of osteoporotic fractures. Arch Intern Med. 1996;156(14):1521-5.

5. Hannan EL, Magaziner J, Wang JJ, Eastwood EA, Silberzweig SB, Gilbert M, et al. Mortality and locomotion 6 months after hospitalization for hip fracture: risk factors and risk-adjusted hospital outcomes. JAMA. 2001;285(21): 2736-42.

6. U.S. Department of Health and Human Services, Bone Health and Osteoporosis: A Report of the Surgeon General. Rockville, MD: U.S. Department of Health and Human Services, Office of the
Surgeon General, 2004. Available at: http://www.surgeongeneral. gov/library.

7. NIH (National Institute of Health). Consensus Development Panel on Osteoporosis Prevention, Diagnosis, and Therapy. Osteoporosis: prevention, diagnosis, and therapy. J Am Med Assoc. 2001;85:785-95.

8. Sampaio PRL, Bezerra AJC, Gomes L. A osteoporose e a muIher envelhecida: fatores de risco. Rev Bras Geriatr Gerontol. 2011;14(2):295-302.

9. Neto A, Soares A, Urbanetz A, Souza A, Ferrari A, Amaral B, et al. Brazilian consensus on osteoporosis. Rev Bras Reumatol. 2002;42(6): 344-54.

10. Marinho B, Soares M. Custo-efetividade da investigação laboratorial da osteoporose. Arch Osteoporos. 2012;7(Suppl):S191 (abstract).

11. Instituto Brasileiro de Geociências e Estatística (IBGE). Censo 2010. Distribuição da população por sexo, segundo os grupos de idade. Available at: http://www.ibge.gov.br/home/estatistica/ populacao/censo2000/.

12. Martini LA, Moura EC, Santos LC, Malta DC, Pinheiro Mde M. Prevalence of self-reported diagnosis of osteoporosis in Brazil, 2006. Rev Saude Publica. 2009;43 Suppl 2:107-16.

13. Morales-Torres J, Gutierrez-Urena S. Osteoporosis Committee of Pan-American League of Associations for Rheumatology. The burden of osteoporosis in Latin America. Osteoporos Int. 2004;15(8):625-32.

14. Fontes T, Araújo L, Soares P. Osteoporosis in climacteric I: epidemiology, definition, screening and diagnosis. Femina. 2012;40(2):109-16.

15. Pinheiro MM, Eis SR. Epidemiology of osteoporotic fractures in Brazil: what we have and what we need. Arq Bras Endocrinol Metabol. 2010;54(2):164-70.

16. Pinheiro MM, Ciconelli RM, Martini LA, Ferraz MB. Clinical risk factors for osteoporotic fractures in Brazilian women and men: the Brazilian Osteoporosis Study (BRAZOS). Osteoporos Int. 2009;20(3):399-408.

17. Camargo MB, Cendoroglo MS, Ramos LR, de Oliveira Latorre Mdo R, Saraiva GL, Lage A, et al. Bone mineral density and osteoporosis among a predominantly Caucasian elderly population in the city of Sao Paulo, Brazil. Osteoporos Int. 2005;16(11):1451-60.

18. Pinheiro M, Reis Neto E, Yang J, Machado F, Omura F, Szejnfeld $J$, et al. Risk factors for osteoporotic fractures and low bone density in pre and postmenopausal women. Rev Saude Publica. 2010;44(3):479-85.

19. Baccaro LF, de Souza Santos Machado V, Costa-Paiva L, Sousa $\mathrm{MH}$, Osis MJ, Pinto-Neto AM. Factors associated with osteoporosis in Brazilian women: a population-based household survey. Arch Osteoporos. 2013;8(1-2):138.

20. Buttros Dde A, Nahas-Neto J, Nahas EA, Cangussu LM, Barral $A B$, Kawakami MS. [Risk factors for osteoporosis in postmenopausal women from southeast Brazilian]. Rev Bras Ginecol Obstet. 2011;33(6):295-302.

21. Hernandes ES, Lebrao ML, Duarte YA, Santos JL. [Health insurance coverage of the elderly and socioepidemiological characteristics associated]. Rev Saude Publica. 2012;46(6):1030-8.

22. Clark P, Cons-Molina F, Deleze M, Ragi S, Haddock L, Zanchetta JR, et al. The prevalence of radiographic vertebral fractures in Latin American countries: the Latin American Vertebral Osteoporosis Study (LAVOS). Osteoporos Int. 2009;20(2):275-82.

23. Castro da Rocha FA, Ribeiro AR. Low incidence of hip fractures in an equatorial area. Osteoporos Int. 2003;14(6):496-9.

24. Pinheiro MM, Ciconelli RM, Jacques Nde O, Genaro PS, Martini LA, Ferraz MB. The burden of osteoporosis in Brazil: regional data 
from fractures in adult men and women--the Brazilian Osteoporosis Study (BRAZOS). Rev Bras Reumatol. 2010;50(2):113-27.

25. Siqueira FV, Facchini LA, Hallal PC. The burden of fractures in Brazil: a population-based study. Bone. 2005;37(2):261-6.

26. Oliveira PP, Marinheiro LP, Wender MC, Roisenberg F, Lacativa PG. [Prevalence of vertebral fractures and risk factors in women over 60 years of age in Chapeco, Santa Catarina State, Brazil]. Cad Saude Publica. 2010;26(9):1777-87.

27. Lopes JB, Figueiredo CP, Caparbo VF, Takayama L, Menezes PR, Scazufca M, et al. Osteoporotic fractures in the Brazilian community-dwelling elderly: prevalence and risk factors. J Clin Densitom. 2011;14(3):359-66.

28. Bulletin of the World Health Organization. Round Table Discussion. 1999;77(5):423-35. Available at: http://www.ncbi.nlm.nih. gov/pmc/articles/PMC2557664/pdf/10361763.pdf.

29. Pesquisa Firme Forte Osteoporose, 2012. Available at: http:// www.sejafirmeforte.com.br.

30. Garcia R, Leme MD, Garcez-Leme LE. Evolution of Brazilian elderly with hip fracture secondary to a fall. Clinics (Sao Paulo). 2006;61(6):539-44.

31. Lopes JB, Fung LK, Cha CC, Gabriel GM, Takayama L, Figueiredo $\mathrm{CP}$, et al. The impact of asymptomatic vertebral fractures on quality of life in older community-dwelling women: the Sao Paulo Ageing \& Health Study. Clinics (Sao Paulo). 2012;67(12):1401-6.

32. de Oliveira Ferreira N, da Silva RB, Arthuso M, Pinto-Neto AM, Caserta N, Costa-Paiva L. Prevalence of vertebral fractures and quality of life in a sample of postmenopausal Brazilian women with osteoporosis. Arch Osteoporos. 2012;7(1-2):101-6.

33. Fortes EM, Raffaelli MP, Bracco OL, Takata ET, Reis FB, Santili C, et al. [High morbid-mortability and reduced level of osteoporosis diagnosis among elderly people who had hip fractures in Sao Paulo City]. Arq Bras Endocrinol Metabol. 2008;52(7):1106-14.

34. Pereira SR, Puts MT, Portela MC, Sayeg MA. The impact of prefracture and hip fracture characteristics on mortality in older persons in Brazil. Clin Orthop Relat Res. 2010;468(7):1869-83.

35. Bortolon P, Andrade C, Andrade C. O perfil das internações do SUS para fratura osteoporótica de fêmur em idosos no Brasil: uma descrição do triênio 2006-2008. Cad Saude Publica. 2011;27(4):733-42.

36. Vidal El, Coeli CM, Pinheiro RS, Camargo KR Jr. Mortality within 1 year after hip fracture surgical repair in the elderly according to postoperative period: a probabilistic record linkage study in Brazil. Osteoporos Int. 2006;17(10):1569-76.

37. Pinheiro MM, Castro CM, Szejnfeld VL. Low femoral bone mineral density and quantitative ultrasound are risk factors for new osteoporotic fracture and total and cardiovascular mortality: a 5-year population-based study of Brazilian elderly women. J Gerontol A Biol Sci Med Sci. 2006;61(2):196-203.

38. Brandao CM, Machado GP, Acurcio Fde A. Pharmacoeconomic analysis of strategies to treat postmenopausal osteoporosis: a systematic review. Rev Bras Reumatol. 2012;52(6):924-37.

39. Johnson BE, Lucasey B, Robinson RG, Lukert BP. Contributing diagnoses in osteoporosis. The value of a complete medical evaluation. Arch Intern Med. 1989;149(5): 1069-72.

40. Cerda Gabaroi D, Peris P, Monegal A, Albaladejo C, Martinez MA, Muxi $A$, et al. Search for hidden secondary causes in postmenopausal women with osteoporosis. Menopause. 2010;17(1):135-9.

41. Cooper A, Brew S, de Lusignan S. The effectiveness of blood tests in detecting secondary osteoporosis or mimicking conditions in postmenopausal women. Br J Gen Pract. 2002;52(477):311-3.

42. Tannenbaum C, Clark J, Schwartzman K, Wallenstein S, Lapinski $\mathrm{R}$, Meier $\mathrm{D}$, et al. Yield of laboratory testing to identify secondary contributors to osteoporosis in otherwise healthy women. J Clin Endocrinol Metab. 2002;87(10):4431-7.

43. Rajeswaran C, Spencer J, Barth JH, Orme SM. Utility of biochemical screening in the context of evaluating patients with a presumptive diagnosis of osteoporosis. Clin Rheumatol. 2007;26(3):362-5.

44. Stewart P.The adrenal cortex. In: Williams Textbook of Endocrinology. Melmed S, Polonsky KS, Larsen PR, Kronenberg HM, Editor. 2002, Saunders: Philadelphia. p. 491-551.

45. Silva T, Furnaletto T. Diagnóstico de doença celíaca em adultos. Rev Assoc Med Bras. 2010;56(1):122-6.

46. Hodgson SF, Watts NB, Bilezikian JP, Clarke BL, Gray TK, Harris DW, et al. American Association of Clinical Endocrinologists medical guidelines for clinical practice for the prevention and treatment of postmenopausal osteoporosis: 2001 edition, with selected updates for 2003. Endocr Pract. 2003;9(6): 544-64.

47. Bahia L, Costa A, Fernandes C, Luiz RR, Cavalcanti MdLT. Segmentation of the demand of the plans and private insurances of health: an analysis of the information of PNAD/98. Ciênc Saúde Coletiva. 2002;7(4):671-86.

48. Brandão CMR, Júnior AAG, Cherchiglia ML, Andrade EIG, Almeida AM, Silva GDd, et al. Gastos do Ministério da Saúde do Brasil com medicamentos de alto custo: uma análise centrada no paciente. Value in Health. 2011;14(5):S71-7.

49. Kowalski SC, Sjenzfeld VL, Ferraz MB. Resource utilization in postmenopausal osteoporosis without incident fractures. J Rheumatol. 2004;31(5):938-42.

50. Brandao CM, Ferre F, Machado GP, Guerra AA Jr, Andrade El, Cherchiglia ML, et al. [Public spending on drugs for the treatment of osteoporosis in post-menopause]. Rev Saude Publica. 2013;47(2):390-402.

51. Bracco O, Fortes E, Raffaelli M, Araújo D, Santili C, Castro M. Custo hospitalar para tratamento da fratura aguda do fêmur por osteoporose em dois hospitais-escola conveniados ao Sistema Único de Saúde. J Bras Econ Saúde. 2009;1(1):3-10.

52. Araujo DV, Oliveira JH, Bracco OL. [Cost of osteoporotic hip fracture in the Brazilian private health care system]. Arq Bras Endocrinol Metabol. 2005;49(6):897-901.

53. Silva LK. [Technology assessment in health care: bone densitometry and alternative therapies in post-menopausal osteoporosis]. Cad Saude Publica. 2003;19(4):987-1003.

54. Araújo D, Bahia L, Souza C, Fernandes R, Navarro J, Bueno R. Análise de custo-efetividade do ácido zoledrônico na prevenção da fratura osteoporótica proximal de fêmur no cenário do Sistema Suplementar de Saúde Brasileiro. Rev Bras Geriatr Gerontol. 2008;11(3):357-68.

55. Pinheiro MM, Reis Neto ET, Machado FS, Omura F, Szejnfeld J, Szejnfeld VL. Development and validation of a tool for identifying women with low bone mineral density and low-impact fractures: the Sao Paulo Osteoporosis Risk Index (SAPORI). Osteoporos Int. 2012;23(4):1371-9. 